\title{
Recusa e hesitação vacinal e os seus efeitos para os sistemas universais de saúde
}

\author{
Roberta Karoleen Moura NOBRE: Curso de Especialização em Economia e Gestão em Saúde, \\ Faculdade de Saúde Pública - FSP, Universidade de São Paulo - USP. ORCID: \\ https://orcid.org/0000-0002-5586-1604 \\ Lúcia Dias da Silva GUERRA: Professora do Curso de Nutrição, Centro Universitário \\ Anhanguera/campus Santana. Faculdade de Saúde Pública - FSP, Universidade de São Paulo - \\ USP. ORCID: https://orcid.org/0000-0003-0093-2687
}

\section{Resumo}

A Organização Mundial de Saúde (OMS) criou em 2012, o Plano de Ação Global para Vacinas (ou em inglês GVAP) adotado por 194 países, cujo objetivo é a prevenção de milhões de mortes até 2020, por meio do acesso universal à imunização. Mesmo diante de anos de turbulência, em 1971 foi notificado o último caso de varíola no Brasil, sendo esse um grande marco de ação sanitária para o país, fruto de importante campanha de vacina ocorrida nos anos 60. Em 1973, foi formulado o Programa Nacional de Imunizações (PNI) pelo Ministério da Saúde, que em 1975 foi institucionalizado. A criação do PNI foi fundamental para assegurar a uniformidade do calendário vacinal, a introdução sustentável de novas vacinas, a padronização técnica e a adoção de estratégias inovadoras, como a combinação de vacinação de rotina, com campanhas de vacinação que tiveram um papel essencial na eliminação de doenças, como a poliomielite e o sarampo. Ainda que, muitos países tenham alcançado a erradicação de algumas doenças, nota-se uma crescente negativa da vacinação no Brasil e no mundo. Esse não é um fenômeno novo, porém vem retornando com força à medida em que as doenças foram desaparecendo. Outro importante fator crescente nos últimos anos é o advento da internet e do contínuo uso das redes sociais para a divulgação de informações falsas, chamadas de "fake news". O número de indivíduos que recusam ou hesitam a vacinação vem crescendo nos últimos anos. Esse movimento tem sido notado com a diminuição da cobertura vacinal, porém é importante diferenciá-los: a recusa é o ato de recusar a vacinação; já a hesitação vacinal é definida como o atraso em aceitar ou recusar certas vacinas recomendadas, apesar da sua disponibilidade nos serviços de saúde. Há autores do campo do direito sanitário que indagam se a vacinação é um direito ou um dever? e alertam para a emergência de um paradoxo sanitário e suas consequências para a saúde pública. Diante deste cenário de recusa e hesitação vacinal crescentes, faz-se necessário conhecer quais os efeitos que estes fenômenos têm trazido para os sistemas universais de saúde. O estudo é uma revisão integrativa, que tem como pergunta norteadora "Quais os efeitos da recusa e hesitação vacinal nos sistemas universais de saúde?". O desenvolvimento para esta revisão teve como base inicial o planejamento e pré-teste para definição da pergunta, definição das bases de dados, dos termos/descritores no DeCS (Descritores em Ciências da Saúde da Biblioteca Virtual em Saúde - BVS) e construção da estratégia de busca. A busca e a seleção das bibliografias na base de dados disponíveis no acervo da Biblioteca Virtual da Saúde (BVS), 
foram realizadas com a inserção dos descritores da pesquisa para identificar artigos cujos descritores tinham relação. A partir do resultado encontrado, os descritores foram divididos em dois itens-chaves, sendo: universal relacionado aos sistemas universais de saúde (Fenômeno/Contexto), recusa e vacina relacionados a recusa vacinal (Objeto). A sintaxe foi construída com base nos itens identificados na pergunta da pesquisa e dividida em três polos: 'RECUSA', 'VACINA' e 'UNIVERSAL'. Para obtenção de abrangência nas buscas, foi utilizada a técnica do funil com a busca avançada pesquisando diversos cruzamentos em 5 base de dados, sendo elas BVS (Lilacs), Scielo, Pubmed (Medline), Scopus e Embase. Foram selecionadas publicações nos idiomas português, inglês e espanhol, e artigos científicos. Outros tipos de publicações não permaneceram na revisão. Considerando os três polos, foram selecionados os cruzamentos que apresentaram resultados mais expressivos na tentativa de responder à pergunta de pesquisa. A sintaxe final da busca foi (recusa de vacinação) OR (recusa de vacina) OR (movimento contra vacinação) OR (movimento antivacinação) OR (doenças preveníveis por vacina) OR (vacinação obrigatória) AND (cobertura universal de saúde) OR (estratégias para cobertura universal de saúde). Essa sintaxe também foi utilizada em espanhol: (Negativa a la Vacunación) OR (Vacunación) OR (Enfermedades prevenibles por vacunación) AND (Cobertura Universal de Salud) OR (Estrategias para Cobertura Universal de Salud); e em inglês: (Vaccination OR Vaccination Refusal OR Anti-Vaccination Movement OR Vaccine-Preventable Diseases) AND (Universal Health Coverage). Após a busca nas bases de dados, obteve-se 427 publicações, dentre estas, 107 artigos científicos foram encontrados na base de dados BVS (Lilacs), 54 na Scielo, 62 na Pubmed (Medline), 184 na Scopus e 20 na Embase. Do total de 427 publicações, 108 correspondiam a artigos duplicados e livros, que foram retirados da revisão durante o uso do gerenciador Zotero. Dessa forma, chegou-se em 319 artigos científicos para análise de títulos e resumos. Esses artigos foram organizados em uma planilha em Excel e após análise, permaneceram na revisão 35 artigos científicos para realização de leitura na integra. Em análise exploratória dos 35 artigos científicos selecionados que entraram para esta revisão, pode-se observar a diversidade de artigos publicados em diferentes continentes, como América do Norte (Canadá e EUA), Europa (Itália) e América Latina (Brasil). Verificou-se que o período de publicação dos artigos selecionados é de 2005 a 2020, o maior número de publicações advém dos últimos 10 anos ( $n=31 ; 2010-2020)$, sendo que há uma tendência de aumento das publicações nos últimos 4 anos $(n=19 ; 2017-2020)$. Apenas 04 artigos compreendem ao período de 2005-2010. Espera-se que este estudo possa contribuir para a identificação e compreensão dos efeitos crescentes que a recusa e a hesitação vacinal têm trazido para os sistemas universais de saúde. Visando o entendimento da economia política para a saúde pública.

Descritores: Recusa de Vacinação; Movimento contra Vacinação; Doenças Preveníveis por Vacina.

Keywords: Vaccination Refusal; Anti-Vaccination Movement; Vaccine-Preventable Diseases.

Palabras-claves: Negativa a la Vacunación; Movimiento Anti-Vacunación; Enfermedades Prevenibles por Vacunación. 